\title{
Terminalia catappa (Talisay) Leaves for Preliminary Surface Water Treatment: An Eco-Friendly Approachs
}

\section{Bryan $\mathrm{MN}^{*}$}

Cagayan State University, Human Kinetics, Tuguegarao City, Cagayan 3500, Philippines

\begin{abstract}
At present, in order to decrease the hazards of using inorganic coagulants for preliminary water treatment, researchers have been studying the possibility of using new methods and materials to treat water. This study aimed to evaluate the performance of turbidity removal in water by using Terminalia catappa (Talisay) as natural coagulant. The coagulation active agent in the leaves of Terminalia catappa was extracted with 1.0 molar (M) Sodium Chloride $(\mathrm{NaCl})$ solution. Water from Cagayan River, Tuguegarao City, with increased turbidity of 200 Nephelometric Turbidity Units (NTU) was used in this study. This study was done using Completely Randomized Design with loading doses of $2,3,4$, and $5 \mathrm{~mL} / \mathrm{L}$ of the stock solution with $5 \mathrm{~g}$ of Terminalia catappa leaf powder in $100 \mathrm{~mL} 1.0 \mathrm{M} \mathrm{NaCl}$ solution as coagulant. The turbidity, $\mathrm{pH}$, and coliform count were determined for all the samples. The turbidity for the samples ranged from ${ }_{\log 10} 1.81$ to ${ }_{\log 10} 1.33 \mathrm{NTU}$. The $5 \mathrm{ml} / \mathrm{L}$ treatment of Terminalia catappa showed the lowest residual turbidity where $88 \%$ turbidity was removed from the sample. The $\mathrm{pH}$ values ranged from 7.27 to 7.46 . The total coliform count for all treatments were all equivalent with $>6500 \mathrm{cfu} / \mathrm{mL}$. Hence, Terminalia catappa leaf extract possesses potential natural coagulant for surface water treatment due to its ability to remove turbidity. However, Terminalia catappa leaf extract has no effect on the basicity and acidity of the water sample. Furthermore, it has no observable antibacterial property on water.
\end{abstract}

Keywords: Terminalia catappa; Surface water; Turbidity; Coagulant; Coagulation; Flocculation; Flocculant

\section{Introduction}

There has been considerable interest in the development and usage of plant based natural coagulants. The use of plant-based materials as water treatment agents has long history, particularly the wood charcoal as an excellent adsorbent. Natural polyelectrolyte of plant origin has been used for many centuries in developing countries for purification of turbid water. For home water treatment, the plant-based materials have been used in the forms of powder and paste, $90 \%$ of which consists of substances other than the polyelectrolytes. Even under such conditions, few plant seeds make effective coagulants. Several plant-based materials were identified as a natural coagulant such as Moringa (Malunggay), Strychnos (Clearing nut tree) and Cactus [1].

Recently, tannin-based coagulants have been utilized in coagulation/ flocculation process for water purification [2]. Tannins are high molecular weight polycyclic aromatic compounds. Tannins are widely distributed in the plant kingdom obtained from natural materials, for example, the organic extracts from bark and wood of trees such as Acacia, Castanea, or Schinopsis [3]. Interestingly, Terminalia catappa leaves, locally known as Talisay, contains large amount of tannin.

Terminalia catappa believed to have originated in Malaysia. This tree is generally confined to mesic and wet coastal habitats and is distributed throughout the Old World tropics and tropical America (Morton). It is reaching heights of 15 to $25 \mathrm{~m}$. Terminalia catappa shows strong salt-, drought- and wind-tolerance and produces fruit $(5-10 \mathrm{~cm}$ long) with a thin flesh surrounding a large fibrous nut [4].

Terminalia catappa leaves have traditionally been used by Betta (Siamese fighting fish) breeders in South East Asia to mimic the natural Betta habitat. They are believed to aid the fish in a number of ways, such as helping fighting fish heal after a battle and inducing spawning in breeding tanks [5]. The leaves do contain several flavonoids like kamferol or quercetin and several tannins such as punicalin, punicalagin or tercatin, saponins and phytosterols. Due to this chemical richness, the leaves and also the bark have long been used in different traditional medicines for various purposes. It is also thought that the large leaves (7-10" long) contain agents for prevention of cancers and antioxidant as well as anticlastogenic characteristics [6]. In fishkeeping the leaves are also used to lower the $\mathrm{pH}$ and heavy metals of the water. It has been utilized in this way by Betta breeders in Thailand for many years. Hobbyists across the world also use them for conditioning the betta's water for breeding and hardening of the scales.

Turbidity is an important water quality parameter in drinking water provision and treatment. Turbidity is a measure of the cloudiness of water. High turbidity can also have a variety of negative effects on various methods of water use and treatment. Turbidity is measured in different units but commonly measured in Nephelometric Turbidity Units (NTU). According to the Philippine National Standards for Drinking Water in 2007, drinking water should have a turbidity of $\leq 5 \mathrm{NTU}$. This is due to the belief that turbidity becomes visible at approximately $5 \mathrm{NTU}$, and water with any visible turbidity may be rejected in favor of a clearer, possibly more contaminated source. On the other hand, standard $\mathrm{pH}$ level ranges from 6.5-8.5.

Cognizant to the challenges of the continuous pursuit of safe drinking water, this research is deemed beneficial for it yields a practical alternative to inorganic coagulants to save our dependency on these harmful substances in water treatment facilities. The pursuit of this study will lead to meaningful utilization of Terminalia catappa leaves. The use of T. catappa as a natural coagulant/flocculant for surface water treatment can be a factor to domestic health and safety practices. This study founded on the coagulation-flocculation processes, embarked on eco-friendly approaches which inspire healthy living.

${ }^{*}$ Corresponding author: Bryan Mallillin Nozaleda, Cagayan State University, Human Kinetics, Tuguegarao City, Cagayan 3500, Philippines, Tel: +639274213297; E-mail: bnozaleda@gmail.com

Received December 23, 2016; Accepted December 30, 2016; Published January 05, 2017

Citation: Bryan MN (2017) Terminalia catappa (Talisay) Leaves for Preliminary Surface Water Treatment: An Eco-Friendly Approach. Nat Prod Chem Res 5: 249 doi: 10.4172/2329-6836.1000249

Copyright: (C) 2017 Bryan MN. This is an open-access article distributed under the terms of the Creative Commons Attribution License, which permits unrestricted use, distribution, and reproduction in any medium, provided the original author and source are credited. 


\section{Objectives of the Study}

This research was conceptualized to investigate the potential of Terminalia catappa leaf stock solution as a primary natural coagulant in treating surface water. The effectiveness of the coagulant is measured on the final turbidity, $\mathrm{pH}$ level, and coliform count of the water after the treatment.

\section{Materials and Methods}

\section{Study design}

This experimental study used Completely Randomized Design. The experiment investigated the ability of Terminalia catappa leaf stock solution of varied concentrations in turbidity removal, its effect to the $\mathrm{pH}$ and coliform count of the water. Primarily, Jar test equipment was used for the coagulation-flocculation process. There were replicates for the Jar testing in order to utilize averaging on the turbidity, $\mathrm{pH}$ level and coliform count of the water at the end of the treatment.

\section{Collection of water sample}

Twenty liters of water was collected from Cagayan River located at Buntun, Tuguegarao City. Based on the water collection procedure set by Philippine National Standards for Drinking Water (2007), the water samples used in this study were taken in the middle of the river and at mid-depth. The turbidity of the water was further increased to 200 NTU by mixing clay particles in the water. The clay was mixed vigorously in the water. The mixture was then left overnight to allow complete hydration of the clay particles. The supernatant was collected carefully and transferred in a water jar. The collected water was then transferred to 18 beakers of $1 \mathrm{~L}$ volume.

\section{Preparation of plant stock solution}

Fallen leaves of Terminalia catappa were obtained from Cagayan State University, Carig Campus. The leaf samples have an average length of $17.78 \mathrm{~cm}$. The T. catappa leaves with dark to light red in color were chosen. The leaves were air-dried then cut into small pieces and dried in the oven at $90^{\circ} \mathrm{C}$ for 12 hours to remove the remaining moisture. The leaves were ground to fine powder by using a dry miller. The powdered leaves were kept in shelled container under ambient temperature. The extraction of coagulation active agent was carried out by mixing $5.0 \mathrm{~g}$ Terminalia catappa leaves, $100 \mathrm{~mL}$ of extraction solution and blended for 2 minutes. The extraction solution consisted of $1.0 \mathrm{M} \mathrm{NaCl}$ was used to extract the coagulation active agent. The slurry from extraction process was filtered through filter paper and the filtrate was utilized as a $50 \mathrm{~g} / \mathrm{L}$ Terminalia catappa leaf stock solution. The stock solution of the coagulant was only used in a day.

\section{Data gathering procedure}

The jar test was performed to evaluate the effect of coagulant dosage on turbidity removal efficiency in surface water. The equipment used for the jar test was an improvisation of the actual unit. The experiment was carried out using different concentrations of the Talisay stock solution which was extracted with $1.0 \mathrm{M} \mathrm{NaCl}$. All four $1000 \mathrm{~mL}$ beakers were initially filled with water samples and were placed in the slots of jar tester and were subsequently agitated at $150 \mathrm{rpm}$ for two minutes. Different amount of coagulant ranging between 2.00$5.00 \mathrm{ml} / \mathrm{L}$ were added into each of the beaker during agitation and the process was left for 5 minutes. The mixing was reduced to $30 \mathrm{rpm}$ and continued to agitate for 45 minutes. After agitation process all samples were placed in ambient room temperature for approximately one hour. A pH Meter Quality Probe was used to measure the acidity and basicity of the water making sure the electrode did not touch the beaker. Twenty $\mathrm{mL}$ was obtained from the supernatant and was placed in two test tubes for spectrophotometric measurement of turbidity and coliform count. Turbidity was then measured by pouring the supernatant to the turbidity tube until turbidity measure is read [7]. From the turbidity measure, percent transmittance was calculated.

\section{Statistical analysis}

Analysis of Variance (ANOVA, General Linear Model Procedure) was done to assess whether significant $(\mathrm{p}<0.05)$ variations existed among the treatments given to assess their efficacy as water coagulants. Multiple mean comparisons using Least Significant Difference (LSD) were computed to ascertain where the differences existed. Analysis of data was computed using IBM SPSS Statistics v.20, 2011.

\section{Results and Discussion}

\section{Turbidity}

The untreated water has still the highest turbidity as expected. It is observable that there was a decrease in turbidity respective to the treatments of Terminalia catappa leaf stock solution ranging from ${ }_{\log 10} 1.81 \mathrm{NTU}$ to ${ }_{\log 10} 1.33 \mathrm{NTU}$. A concentration of $5 \mathrm{ml} / \mathrm{L}$ of Terminalia catappa worked best in terms of turbidity removal among the four treatments of the stock solution at ${ }_{\log 10} 1.33$ NTU (Table 1).

Consequently, transmittance values show also the same data pattern vis-à-vis turbidity as shown in Figures 1 and 2. 72.4\% transmittance was observed at $5 \mathrm{ml} / \mathrm{L}$ concentration, considerably lower than $83.3 \%$ transmittance for $5 \mathrm{ml} / \mathrm{L}$ of Alum.

As shown in Tables 2-5, extract of Terminalia catappa leaves has potential to remove turbidity of raw water sample. It was observed that as the amount of coagulant dose increases its capacity to remove turbidity also increases. Best result was observed at optimum dose of 5 $\mathrm{ml} / \mathrm{L}$ at which $88 \%$ turbidity was removed from the water sample.

Moreover, there is a significant difference among the final turbidity of the water treated with different concentrations of Terminalia catappa leaf stock solution. At $p$ value, $p<0.05$, there is also a statistically significant difference among the transmittance values. This confirms that Terminalia catappa leaves have indeed a coagulation property and has a potential to be a coagulant. This observation could be attributed to the tannins in the leaves destabilizing the suspended particles' charges in the water of Terminalia catappa supported by the study of Ozacar and

\begin{tabular}{|c|c|c|}
\hline Treatment & & Mean \\
\hline Turbidity & Control & 2.3000 \\
\hline \multirow{4}{*}{ Transmittance } & A5 & 0.9900 \\
\cline { 2 - 3 } & T2 & 1.8133 \\
\cline { 2 - 3 } & T3 & 1.7333 \\
\hline \multirow{3}{*}{} & T4 & 1.6500 \\
\hline \multirow{3}{*}{} & T5 & 1.3333 \\
\hline & Total & 1.6367 \\
\hline & Control & 54.6000 \\
\hline & A5 & 83.3000 \\
\hline & T2 & 54.9000 \\
\cline { 2 - 3 } & T3 & 58.9667 \\
\cline { 2 - 3 } & T4 & 67.9333 \\
\hline & T5 & 72.4000 \\
\hline
\end{tabular}

Table 1: Mean turbidity levels in NTU and \% transmittance of the water after the treatments. 


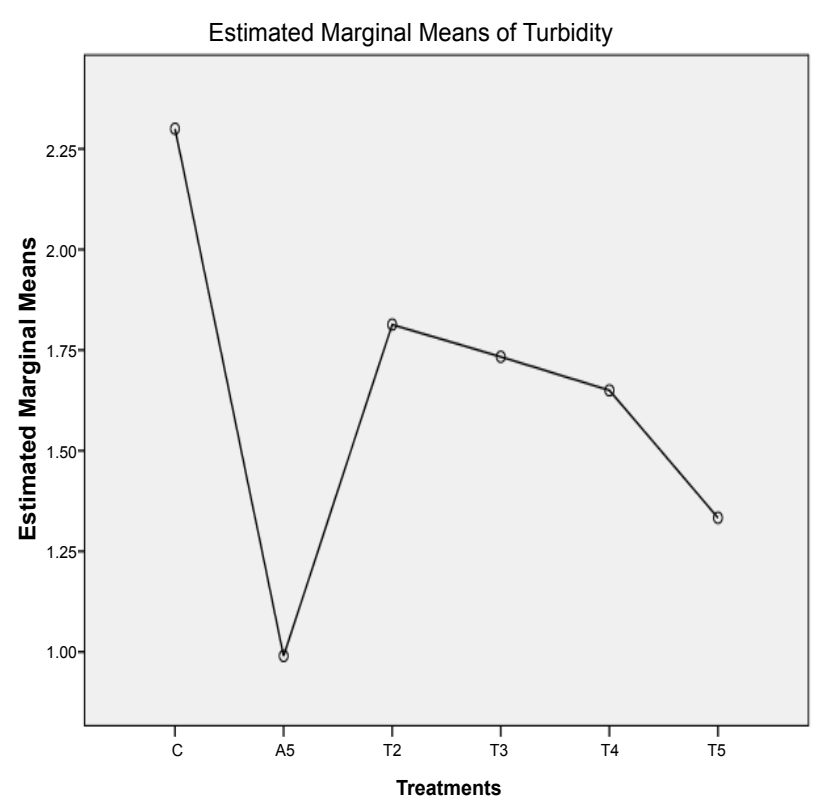

Figure 1: Effect of Terminalia catappa as coagulant at varying concentrations in turbidity.

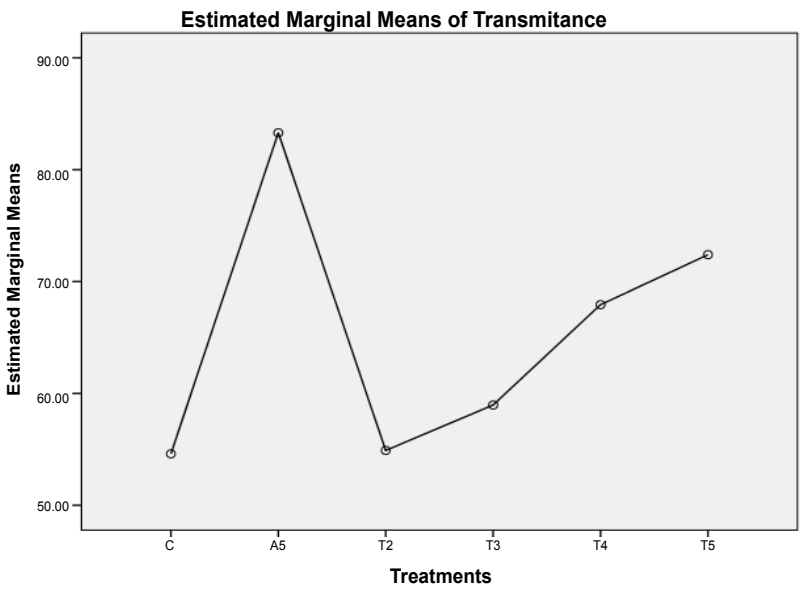

Figure 2: Effect of as coagulant at varying concentrations in transmittance.

Sengil in 2001 using tannins extracted from Turkish Corns as coagulant and coagulant aid [8].

\section{pH}

It is observable to all treatments of Terminalia catappa that the $\mathrm{pH}$ increases as compared to the control groups ( $\mathrm{C}$ and $\mathrm{A} 5$ ). Although there is small discrepancy between $\mathrm{T} 4$ and $\mathrm{T} 5$, a decreasing $\mathrm{pH}$ is observed as the concentration of Terminalia catappa increases to $5 \mathrm{ml} / \mathrm{L}$. Water treated with alum has the lowest $\mathrm{pH}$ among groups. This result can be supported by the fact that Terminalia catappa leaves contain tannins which lowers the $\mathrm{pH}$ of water; hence used in aquaria as water conditioners especially to Beta-Siamese fishing (http://aquariadise. com/indian-almond-leaves/). There was no significant difference among the $\mathrm{pH}$ of the water after treating with different concentrations of Terminalia catappa $(\mathrm{p}=0.167)$.

\section{Coliform count}

Based on the equivalent coliform counts of $>6500$ from all the treatments, it can be said that there was no observable antibacterial property of Terminalia catapppa to water. Consequently, with equivalent means, there is no significant difference among the treatments. This sameness of coliform counts among treatments could be explained by the fact that the source of water may have been highly contained with many forms of bacteria where the concentration of Terminalia catappa coagulant and Alum may not be sufficient. Accordingly, after coagulation and flocculation processes the water still has to be subjected for disinfection by chlorination to completely kill pathogens and other microbes in the water during water treatment.

\section{Alum vs Terminalia catappa}

There is a significant difference between the mean turbidity values of the water treated with $5 \mathrm{ml} / \mathrm{L}$ of Alum and $5 \mathrm{ml} / \mathrm{L}$ of Terminalia catappa leaf stock solution. It further shows that Alum works better as coagulant than Terminalia catappa. There is, however, no significant difference between the mean transmittance values $(\mathrm{p}=0.245)$ and $\mathrm{pH}$ levels ( $\mathrm{p}=0.251$ ) of the water treated with Alum and Terminalia catappa. An Independent Sample T-test was run to support this conclusion. It is interesting to note that a $p$-value of greater than 0.005 from $p=0.045$ is needed to show that Alum and Terminalia catappa have no significant difference in terms of its performance in turbidity removal.

\begin{tabular}{|c|c|c|}
\hline Treatment & Residual Turbidity (NTU) & $\%$ of Residual Turbidity \\
\hline $2 \mathrm{ml} / \mathrm{L}$ & 67.35 & 34 \\
\hline $3 \mathrm{ml} / \mathrm{L}$ & 57.17 & 28 \\
\hline $4 \mathrm{ml} / \mathrm{L}$ & 45.73 & 23 \\
\hline $5 \mathrm{ml} / \mathrm{L}$ & 23.26 & 12 \\
\hline Blank & 200.71 & 100 \\
\hline
\end{tabular}

Table 2: Residual turbidity of the water treated with Terminalia catappa leaf stock solution.

\begin{tabular}{|c|c|c|}
\hline Treatment & & Mean \\
\hline \multirow{4}{*}{$\mathrm{pH}$} & Control & 7.1100 \\
\cline { 2 - 3 } & A5 & 7.0600 \\
\cline { 2 - 3 } & T2 & 7.4633 \\
\cline { 2 - 3 } & T3 & 7.3367 \\
\cline { 2 - 3 } & T4 & 7.2433 \\
\hline \multirow{4}{*}{} & T5 & 7.2767 \\
\hline & Total & 7.2483 \\
\hline
\end{tabular}

Table 3: Mean $\mathrm{pH}$ levels of the water after the treatments.

\begin{tabular}{|c|c|c|}
\hline Treatment & & Mean \\
\hline \multirow{4}{*}{ Coliform } & Control & 6500.00 \\
\cline { 2 - 3 } & A5 & 6500.00 \\
\cline { 2 - 3 } & T2 & 6500.00 \\
\cline { 2 - 3 } & T3 & 6500.00 \\
\cline { 2 - 3 } & T4 & 6500.00 \\
\cline { 2 - 3 } & T5 & 6500.00 \\
\hline
\end{tabular}

Table 4: Mean Coliform Counts of the Water.

\begin{tabular}{|c|c|c|}
\hline Dependent Variable & Mean Difference (I-J) & Sig. \\
\hline Turbidity A5 T5 & $-.3433^{*}$ & 0.008 \\
Transmittance A5 T5 & 10.9000 & 0.083 \\
pH A5 T5 & -.2167 & 0.090 \\
\hline
\end{tabular}

Table 5: Significant ANOVA between alum and Terminalia catappa coagulant of equal concentration. 


\section{Conclusions and Recommendations}

Terminalia catappa leaf extract possesses potential natural coagulant for surface water treatment due to its ability to remove turbidity. However, Terminalia catappa leaf extract has no effect on the basicity and acidity of the water sample. Furthermore, it has no observable antibacterial property on water.

The conduct of a parallel study using higher concentrations of Terminalia catappa leaf stock solution is recommended. Future study on the utilization of the seeds and bark of Terminalia catappa as coagulant and further make a comparative study of these parts including its leaves may also be experimented. The study also recommends the use of an actual jar test to simulate coagulation-flocculation process and a digital turbidimeter to measure turbidity in order to increase the reliability of results. This study likewise recommends the conduct of a study using combination treatment of alum and Terminalia catappa in different proportions in order to investigate effectiveness in treating raw water and further to investigate the antibacterial property of Terminalia catappa to water. To determine the relationship between the tannins or protein content to turbidity removal, the isolation and characterization of coagulation active agent in Terminalia catappa's leaves through Fourier Transform Infrared Spectroscopy (FTIR) analysis may also be done. Furthermore, a comparative analysis on the performance of Terminalia catappa leaves when the coagulation active agents are extracted with the use of other techniques with Soxhlet apparatus may also be performed.

\section{References}

1. Rani CN, Jadhav MV (2012) Enhancing Filtrate Quality of Turbid Water Incoporating Seeds of Strychnos potatorum, Pads of Cactus opuntia and Mucilage Extracted from the Fruits of Coccinia indica as Coagulants. Journal of Environmental Research and Development 7.

2. Yin CY (2010) Emerging Usage of Plant-Based Coagulants for Water and Waste-water Treatment. Process of Biochemistry 45: 1437-1444.

3. Sanchez-Martin J, Gonzales VM, Beltran-Heredia J, Gragera C, Salguero FJ (2010) Novel Tannin-based Adsorbent in Removing Cationic Dye (Methylene blue) from Aqueous Solution. Kinetics and Equilibrium studies. Journal of Hazardous Materials 174: 9-16.

4. Chen PS, Jih H, Liu TY, Lin TC (2000) Folk Medicine Terminalia catappa and its Major Tannin Compound, Punicalagin are effective against Bleomycin-Induced Genotoxicity in Chinese Hamster Ovary Cells. Cancer Letters 152: 115-122.

5. Gupta S, Mishra P (2011) Role of Immunomodulatory Plants in Pisciculture. Asian Journal of Bioscience. Asian Journal of Bio Science 6: 147-151.

6. Chyau CC, Tsai SY, Ko PT, Jeng-Leun M (2002) Antioxidant Poperties of solvent Extracts from Terminalia catappa Leaves. Food Chemistry 78: 483-488.

7. Myre E, Shaw R (2006) The Turbidity Tube: Simple and Accurate Measurement of Turbidity in the Field. Michigan Technological University.

8. Ozacar M, Sengil IA (2003) Evaluation of Tannin Biopolymer as a Coagulant Aid for Coagulation of Colloidal Particles. Colloids and Surfaces A: Physicochemical and engineering Aspects 229: 85-96. 